Apresentação | Introduction

http://dx.doi.org/10.1590/S0104-71832020000100002

\title{
Da arte de imitar
}

\section{On the art of imitation}

\section{Ruben George Oliven ${ }^{\star}$}

* Universidade Federal do Rio Grande do Sul - Porto Alegre, RS, Brasil ruben.oliven@gmail.com https://orcid.org/0000-0003-3556-6955

\section{Louise Scoz Pasteur de Faria**}

** Universidade Federal do Rio Grande do Sul - Porto Alegre, RS, Brasil louisescoz@gmail.com

https://orcid.org/0000-0002-2140-6523

\section{Arlei Sander Damo ${ }^{\star \star *}$}

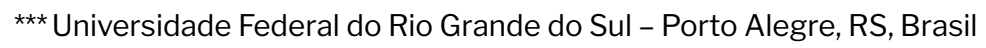
arleidamo@gmail.com

https://orcid.org/0000-0003-4368-6754 
Há várias palavras para designar o ato de copiar. Algumas são positivas: emulação, réplica, citação, paráfrase, paródia, mimesis. Outras são negativas: imitação, arremedo, pastiche, simulacro, falsificação, pirataria, plágio, cola, fake. A valorização ou desvalorização depende obviamente do lado em que nos encontramos. Só imitamos aquilo que admiramos. Os filhos, quando pequenos, imitam os gestos dos pais. Adolescentes seguem o comportamento de "role models", que podem ser irmãos mais velhos, professores ou líderes. Aprendemos algumas das coisas mais importantes da nossa vida, copiando o que os mais velhos fazem. A imitação faz parte do desenvolvimento humano. Nas palavras do reverendo inglês Charles Caleb Colton (1780-1832), "a imitação é a forma mais sincera de lisonja” (Colton, 1824, p. 114, tradução nossa).

A habilidade mimética dos seres humanos interessou aos antropólogos desde o começo de sua disciplina. A capacidade de criar uma segunda natureza, de copiar, imitar, trapacear, simular, disfarçar, enganar e até mesmo falsificar é intimamente atrelada à produção da diferença. Desde que Mauss, em seu ensaio "Les techniques du corps", escrito em 1934, ao mostrar a relação entre natureza e cultura, cunhou o conceito de imitação prestigiosa, o termo tem sido central nas ciências sociais. Ele associou os múltiplos usos do corpo - "o primeiro e mais natural instrumento do homem" (Mauss 2003, p. 407) - às noções de hierarquia social e prestígio. Para Mauss, a imitação não é somente uma forma de educar os sentidos para executar tarefas cotidianas, mas também um mecanismo de interação e regulação social. Indivíduos tomam emprestada uma série de movimentos desempenhados por outros e incorporam aqueles que foram executados com sucesso por pessoas que detêm a confiança e, acima de tudo, a autoridade sobre eles. Assim, o corpo molda seus gestos com base em repetições que se dão a partir de uma imitação prestigiosa. Para Mauss (2003, p. 405), "é precisamente nesta noção de prestígio da pessoa que torna o ator ordenado, autorizado e provado, em relação ao indivíduo imitador, que se encontra todo o elemento social".

Mas, com frequência, a imitação é vista como algo espúrio. Os Estados-nação em geral se preocupam em caracterizar suas culturas como autênticas e únicas. Em O homem: uma introdução à antropologia, livro escrito na década de 30 do século passado, o antropólogo Ralph Linton mostra o quanto isso é ilusório. Ele descreve um dia típico de um cidadão que se considera $100 \%$ norte-americano do seguinte modo: 
O cidadão norte-americano desperta num leito construído segundo padrão originário do Oriente Próximo mas modificado na Europa Setentrional antes de ser transmitido à América. Sai debaixo de cobertas feitas de algodão cuja planta se tornou doméstica na Índia; ou de linho ou de lã ou de seda cujo emprego foi descoberto na China. Todos estes materiais foram fiados e tecidos por processos inventados no Oriente Próximo. Ao levantar da cama faz uso dos "mocassins" que foram inventados pelos índios das florestas do leste dos Estados Unidos e entra no quarto de banho cujos aparelhos são uma mistura de invenções europeias e norte-americanas, umas e outras recentes. Tira o pijama, que é vestuário inventado na Índia e lava-se com sabão que foi inventado pelos antigos gauleses, faz a barba que é um rito masoquístico que parece provir dos sumerianos ou do antigo Egito. [...] De caminho para o "breakfast", pára, para comprar um jornal, pagando-o com moedas, invenção da Líbia antiga. No restaurante, toda uma série de elementos tomados de empréstimo o espera. [...] lê notícias do dia, impressas em caracteres inventados pelos antigos semitas, em material inventado na China e por um processo inventado na Alemanha. Ao inteirar-se das narrativas dos problemas estrangeiros, se for um bom cidadão conservador, agradecerá a uma divindade hebraica, numa língua indo-europeia, o fato de ser cem por cento americano. (Linton, 1962, p. 355-356).

Linton escrevia numa época em que o processo de nation-building dos Estados Unidos estava em pleno andamento e havia a ideia de que isso envolvia um melting pot, um cadinho, em que as culturas originais dos milhões de imigrantes que vieram para o país se fundiriam numa só cultura norte-americana. Era importante que ela fosse considerada autêntica. Daí a crença do cidadão que ele descreve de que tudo que utilizava era $100 \%$ norte-americano. Sabemos, entretanto, que todas as culturas são feitas de empréstimos. O fato de eles virem de fora não os torna inautênticos, pois acabam entrando em novos lugares e se adaptando a estes.

Em A invenção das tradições, Eric Hobsbawm e Terence Ranger assinalaram a importância da invenção das tradições na constituição de nações modernas. Através de uma série de exemplos, eles mostram que rituais e comemorações que são frequentemente apresentadas como antigas foram na verdade inventadas recentemente (Hobsbawm; Ranger, 1984).

Nesse sentido, analisando a importância que o folclore tem na constituição de novas nações, Dundes argumenta que a coleção e estudo do folclore ocorrem 
geralmente em pequenos países (como a Finlândia, a Hungria e a Irlanda) que padecem de autoimagens pobres em comparação com outras nações. Nesse tipo de país ocorre frequentemente o fenômeno que Dorson chamou de fakelore (em que a palavra folk, isto é, povo, é substituída por fake, isto é, falso) e que designaria "a apresentação de escritos espúrios e sintéticos sob a reivindicação de que são folclore genuíno" (Dorson, 1969, p. 60, tradução nossa).

A questão, entretanto, não é saber se uma crença corresponde a algum tipo de realidade fática, mas analisar por que, mesmo sabendo que ela é contrariada pelos fatos, existem grupos que acreditam nela. Examinando o que é considerado um dos exemplos clássicos de fakelore, o poema épico finlandês Kalevala publicado no século XIX, mas apresentado por seu inventor como existindo desde tempos imemoriais, Dundes (1985, p. 10, tradução nossa) assinala que apesar de os folcloristas saberem que ele era uma peça inventada, os finlandeses, inclusive muitos intelectuais, preferiam acreditar que se tratava de um épico folk autêntico:

As forças do romanticismo e do nacionalismo eram - e são - tão poderosas na Finlândia que aquilo que o povo acreditava era - e é - mais importante do que aquilo que era verdade. Assim, se os finlandeses acreditam que o Kalevala é um épico folk, não adianta nada os folcloristas finlandeses (e estrangeiros) assinalarem que o Kalevala é fakelore.

A preocupação com a autenticidade das ideias e dos costumes também é tema recorrente no Brasil quando pensamos em nossa identidade nacional. Analisando a questão da importação intelectual, Roberto Schwarz (1977) argumentou que as ideias estavam "fora do lugar" no Brasil Império. Embora a economia brasileira estivesse durante três séculos baseada na exploração da mão de obra escravizada, parte das elites políticas do país da época aderiu ao ideário liberal que fora criado na e se aplicava à Europa. Todavia, o que prevalecia no Brasil não era a ideia de direitos, mas a do favor paternalista para os brancos que não possuíam terras e a opressão para os escravizados.

Pode-se argumentar, entretanto, que do ponto de vista lógico a escravidão não era incompatível com o liberalismo, pois para as elites brasileiras o escravo era uma mercadoria que estava sujeita a ser usada e trocada como qualquer outra. Nesse sentido, as ideias que vinham de fora e que, segundo Schwarz, 
estariam fora do lugar, entraram num novo lugar onde se adaptaram ao cenário local.

A tese das ideias deslocadas se desvinculou da intenção original de Schwarz, que era a análise da obra de Machado de Assis, e acabou virando senso comum. Há um sentimento muito difundido de que no Brasil as ideias e práticas culturais estariam, em geral, "fora do lugar". A tal ponto é forte essa ideia que o historiador inglês Peter Burke (1997, p. 3) assinala que é difícil para um intelectual estrangeiro entender por que os brasileiros estão obcecados com a noção de empréstimo cultural:

Somos todos "emprestadores" - mesmo quando fazemos parte de culturas "financiadoras", como a francesa, a italiana, a norte-americana ou a chinesa. [...] A ideia de uma cultura "pura", não contaminada por influências externas, é um mito. Como escreveu Fernand Braudel em seu famoso estudo do mundo contemporâneo, "para qualquer civilização, viver é ser capaz de dar, de receber, de emprestar".

A rigor nada está no lugar e tudo sai de um lugar e entra em outro em que é adaptado aos interesses de grupos e a circunstâncias cambiantes. A dinâmica cultural implica um processo de desterritorialização e de reterritorialização. Ideias e práticas que se originam num espaço acabam migrando para outros. Lá elas encontram um ambiente muitas vezes diferente daquele no qual se originaram, mas acabam sendo adaptadas ao novo contexto e por assim dizer "entram no novo lugar".

Uma das riquezas da dinâmica cultural brasileira é justamente a capacidade de digerir criativamente o que vem de fora, reelaborá-lo e dar-lhe um cunho próprio que o transforma em algo diferente e novo. Nesse sentido, algumas das expressões culturais consideradas "tipicamente brasileiras", como o futebol e o carnaval, se originaram no exterior, mas foram adotadas e transformadas em símbolos de identidade nacional (Oliven, 1989).

O Manifesto antropófago, lançado em 1928 por Oswald de Andrade, um dos expoentes da Semana Modernista de 1922, assumiu a cópia como algo criativo na medida em que o canibalismo era uma forma não somente de ingerir o outro, mas também de digeri-lo e transformá-lo em algo novo. O que foi proposto pelo Manifesto antropófago é uma modernidade brasileira que se caracterizaria por saber ingerir e digerir criativamente o que vem de fora. Mais do que isso, o que 
Oswald argumentava é que os brasileiros se dedicaram a essa prática desde o começo de sua história. Por isso, o autor datou o Manifesto como sendo do Ano 374 da Deglutição do Bispo Sardinha, numa referência ao prelado português que naufragou na costa do Brasil e foi comido pelos indígenas em 1554 (Andrade, 1978).

Segundo Moraes (1978, p. 144),

o instinto antropofágico, por um lado, destrói, pela deglutição, elementos de cultura importados; por outro lado, assegura a sua manutenção em nossa realidade, através de um processo de transformação/absorção de certos elementos alienígenas. Ou seja: antes do processo colonizador, havia no país uma cultura na qual a antropofagia era praticada, e que reagiu, sempre antropofagicamente mas com pesos diferentes, ao contato dos diversos elementos novos trazidos pelos povos europeus. É este instinto antropofágico que deve ser agora valorizado pelo projeto cultural defendido por Oswald de Andrade. Ele se caracteriza por defender ferrenhamente a intuição e pelo poder de sintetizar em si os traços marcantes da nacionalidade que garantem a unidade da nação.

Há uma obsessão em torno da noção de autenticidade. Em um artigo clássico sobre a obra de arte na época de sua reprodutibilidade técnica, publicado em 1936, Benjamin (1969) defendeu a ideia de que cada obra arte é única e tem uma aura que lhe é própria. Por mais perfeita que seja a cópia de um quadro, ela nunca terá a aura do original, mesmo que as pessoas que a admirem não sejam capazes de distinguir as duas pinturas. Ao utilizar o termo aura, Benjamin constrói um conceito que é muito próximo ao sagrado. De fato, o que caracteriza o sagrado em relação ao profano é o dom atribuído a um objeto que o distingue de outros objetos materialmente iguais ou semelhantes. Do ponto de vista químico, a água benta é idêntica à que bebemos diariamente; entretanto, do ponto de vista religioso, a água benta tem um caráter sagrado que lhe é conferido pela religião católica. Algo semelhante vale para as bandeiras nacionais que não são apenas pedaços de pano, mas emblemas que simbolizam o Estado-nação e que como tal são sagrados. Não são as características materiais desses objetos que os distinguem dos outros, mas sua singularidade. Essa qualidade constitui um dom conferido por alguma instância que classifica esses objetos como únicos e, portanto, sagrados. Para Benjamin, a aura só existiria na obra 
original. Entretanto, se a aura só existe na obra autêntica, mas vivemos em uma época em que tudo é reprodutível e as cópias são idênticas aos originais, como podemos distinguir entre os dois?

Um notável exemplo etnográfico do poder analítico e reflexivo da imitação é o Hauka, movimento religioso que teve origem na década de 1920 no Níger e que se disseminou rapidamente para outras colônias na África. Baseados nos cultos de possessão dos Songhay, os rituais do Hauka envolviam a imitação de oficiais franceses e a apropriação de seus símbolos de poder. Indivíduos possuídos pelos espíritos dos administradores coloniais arremedavam seu poder de uma forma humorística e ao mesmo tempo aterrorizante, expressando críticas sobre a natureza e o comportamento dos colonizadores. Os franceses, sentindo-se ameaçados pelos rituais Hauka, proibiram suas práticas. O filme Les maîtres fous, filmado em 1953 pelo cineasta e antropólogo Jean Rouche, retratou esses rituais e causou muitas polêmicas entre universitários africanos que estudavam na França e que não se identificavam com as imagens da película (Mayet-Giaume; Rouch; Vos, 1996).

Leituras antropológicas do Hauka abriram caminhos teóricos e de pesquisa que ainda ressoam em produções contemporâneas, enfatizando o potencial criativo, político e subversivo da imitação. O Hauka pode ser visto tanto como uma paródia das cerimônias que os colonizadores traziam para as colônias onde elas se encontravam deslocadas como uma imitação prestigiosa dos rituais dos europeus. Para a vertente que viu no Hauka uma forma de resistência, os praticantes de seus rituais, ao imitarem os desfiles militares e outras formas de poder, estavam na verdade se apropriando de seus signos de poder e debochando da autoridade dos colonizadores. Eles estariam assim procurando subtrair a força vital dos colonizadores. Já para a vertente que enxergou no Hauka uma imitação prestigiosa, os africanos, ao encenarem cerimônias francesas, buscavam adquirir status na sociedade colonial. Assim, de acordo com Ferguson (2002), a adoção de hábitos franceses, em vez de constituir uma forma de resistência ou um modo de importar o colonialismo na sociedade nativa, era na verdade uma forma de ser respeitado pelos europeus. Para esse autor, a presença ambivalente do mimetismo na política cultural colonialista é o ponto de partida para pensar criticamente a ideia de imitação como resistência. Mais do que simplesmente um ato de subversão, a imitação também pode ser pensada em um registro de política de reconhecimento. Imitar o outro não é só chamar 
atenção para suas ambivalências, mas também manifestar um desejo de pertencimento político, moral e ético. Assim,

numa era de independência política, na qual hierarquias raciais explícitas são ilegítimas e a desigualdade é naturalizada por ser culturalizada e espacializada, uma insistência antropológica em interpretar gestos de similitude em termos de paródia e mágica tem o efeito de obscurecer as contínuas reivindicações de africanos e outros de plenos direitos de pertencimento numa sociedade mundial. (Ferguson, 2002, p. 559, tradução nossa).

Imitar, copiar e simular são práticas que envolvem noções de fascínio e perigo. Copiar o outro é incorporar seu caráter, sendo portanto um ato de conhecimento e poder que nos inventa em nossa existência social. Entretanto, a cópia também coloca em suspenso normas e valores que organizam a experiência, e sua potência crítica suscita uma miríade de reações acusatórias e de pânico moral.

Vários autores que lidaram com a pós-modernidade argumentam que vivemos em um mundo feito de ficção e fetiche, em que nada mais é real. Taussig inicia seu livro Mimesis and alterity fazendo referência à capacidade mimética,

a natureza que a cultura usa para criar uma segunda natureza, a faculdade de copiar, imitar, fazer modelos, explorar as diferenças, ceder e se tornar o Outro. O milagre da mimesis reside na cópia se basear no caráter e poder do original, ao ponto de a representação poder mesmo assumir esse caráter e esse poder. (Taussig, 1993, p. xiii, tradução nossa).

Em resposta à ênfase dada à ocularidade que é presente tanto na noção de simulacro como no conceito de aura de Benjamin para pensar fenômenos miméticos, Taussig retoma a questão a partir da perspectiva da alteridade e da produção de diferença. O que está em jogo é a negociação das fronteiras de regimes de verdade e de autoridade e o modo como o corpo é capaz de produzir conhecimento táctil sobre o mundo.

Por esse motivo, a ideia de mimetismo (mimicry) é central nas reflexões de Homi Bhabha (1994) sobre a pós-colonialidade, como uma estratégia ilusória e ao mesmo tempo bastante efetiva do poder colonial. É através da mimetização 
que ocorre a fixação do colonial como forma classificatória e de conhecimento discriminatório. O desejo por emergir como "autêntico" através da mimetização do poder colonial implica um grau de fetichização do Eu e do Outro, abrindo espaço também para a chacota e ridicularização dos costumes.

Atualmente, há numerosos debates que exploram as tênues fronteiras entre o real e o falso: a falsificação de artigos de consumo; políticas de combate à pirataria; o debate sobre plágio; a invenção de tradições culturais; a circulação de rumores, lendas urbanas e notícias falsas; a criação de perfis fake na internet; a falsificação de obras de arte, documentos históricos, fotografias e moedas.

Sabemos, entretanto, que imitar, copiar ou mesmo falsificar faz parte do cotidiano. Por mais que esses procedimentos sejam criticados e frequentemente sancionados negativamente, eles sempre fizeram parte do cotidiano e estão crescendo à medida que tecnologias mais sofisticadas são criadas. Existe um mercado impressionante para obras de artes falsificadas (inclusive presente em museus) e para produtos pirateados. Invertendo Benjamin, poderíamos dizer que existe uma aura na imitação.

Isso suscita uma série de questões. A primeira delas tem a ver com o poder de definir o que é autêntico. Quem tem o poder de dizer o que é original e o que não é? Por mais que existam critérios objetivos para definir certos parâmetros de autenticidade, os casos mostrados ao longo da história apontam que o valor de um bem material ou imaterial está muito distante de suas propriedades intrínsecas. São os jogos de poder, a cultura, a crença e o consenso social que definem tanto o valor de um bem quanto a sua legitimidade. Existem instâncias de consagração que definem a autenticidade dos bens materiais e imateriais. Elas podem estar concentradas na academia, nos críticos de arte, nos agentes religiosos, etc. Essas instâncias tendem a criar um modelo ortodoxo da autenticidade.

Analisando as transformações que a arte primitiva experimenta em centros civilizados, a antropóloga Sally Price (2010) argumenta que para compreendê-la precisamos colocar nosso foco não nos objetos de arte em si, nem nas pessoas que as produzem, mas em quem define, desenvolve e defende a internacionalização desse tipo de arte e sua visão racial, cultural, política e econômica. Um dos principais elementos nesse processo de transformação é o anonimato. "Ser anônima" passa assim a ser um passaporte de autenticidade da arte primitiva quando ela é negociada em centros civilizados. 
$\mathrm{O}$ artista norte-americano J. S. Boggs se especializou em pintar desenhos de cédulas de diferentes moedas nacionais e estrangeiras. Ele procura trocar essas pinturas por bens e serviços e tem sido bem-sucedido nessa tarefa. Existe um mercado para seus retratos de dinheiro, cujo valor tem subido substancialmente. Embora seus desenhos não possam ser confundidos com as cédulas oficiais (ele só as pinta de um lado do papel), ele tem sido perseguido por autoridades financeiras como um falsificador de dinheiro. Ele foi processado e absolvido na Austrália e teve material seu apreendido nos Estados Unidos. Na Inglaterra, quando julgado pela acusação de "reproduzir" notas de libras esterlinas, ele conseguiu ser absolvido argumentando que suas pinturas eram únicas e que na verdade as cédulas emitidas pelo Banco da Inglaterra é que eram reproduções (Hart, 2000, p. 235-237).

Existem muitas diferenças entre o Brasil e os Estados Unidos. Uma delas diz respeito ao modo como são encarados alunos que usam métodos "não heterodoxos" para serem aprovados. No Brasil, copiar de um colega ou de um livro durante uma prova se chama colar. Colar é frequentemente visto como uma forma de aprendizagem. Significa aprender a ser malandro e dar um jeito de passar quando não se estudou. Como diz o ditado, "quem não cola, não sai da escola". Embora se possa ser reprovado, quando pego em flagrante, há uma relativa tolerância com quem olha para a prova de seu vizinho. Poucas pessoas no Brasil se envergonham de dizer que colaram na escola ou na universidade. A própria noção de plágio é de difícil compreensão para muitos estudantes universitários. Acostumados na escola secundária que "fazer pesquisa" é cortar e colar pedaços de textos da internet, os alunos muitas vezes copiam parágrafos inteiros sem se dar ao trabalho de citar a fonte. Em alguns casos justapõem parágrafos de autores de estilos e posições diametralmente opostos, num pastiche pós-moderno.

Nos Estados Unidos, onde a lei é encarada com maior rigor que no Brasil, a situação é diferente. Numa universidade norte-americana, há em geral um código de honra que explicita que colar ou plagiar pode resultar em expulsão (Oliven, 1997). Nesse caso, quem cola, literalmente sai da escola.

Gustavo Lins Ribeiro argumenta que a disseminação de cópias de obras de arte através das tecnologias digitais torna datado o ensaio de Benjamin anteriormente referido. Ao passo que seu texto corresponde à lógica da técnica analógica da reprodução dos anos 1930, atualmente vivemos sob a lógica do 
capitalismo eletrônico informático (Ribeiro 2014, p. 261). Com a internet e o sistema Windows ficou mais complexo determinar o que é original e o que é cópia, embora existam programas que permitem aos professores verificar se um trabalho foi feito pelo aluno ou se ele foi copiado. O "copiar e colar" se tornou algo que fazemos cotidianamente em nosso computador. Assim, podemos eliminar alguém de uma foto, incluir uma pessoa que não estava originalmente lá, acionar um photoshop para tornar a foto mais bonita, e ninguém acha que isso seja exatamente uma falsificação.

O mundo da imitação de mercadorias movimenta milhões de dólares. Para os detentores de marcas, que se sentem prejudicados, trata-se de pirataria. Para os produtores dessas mercadorias, trata-se de réplicas. Em Counterfeit itineraries in the Global South, Rosana Pinheiro-Machado analisa a circulação de mercadorias produzidas na China que chegam no Brasil via Paraguai. De acordo com a autora,

sob o guarda-chuva de direitos de propriedade intelectual, a nova guerra contra a pirataria movimentou forças horizontais e verticais através de uma série de sanções, formações jurídicas e regimes de representação. Enquanto regime de verdade que autorizou intervenção, a noção de pirataria criminalizou pessoas, mercadorias e lugares através do mundo. Seguindo a mesma lógica da "guerra contra as drogas", os resultados dessas operações causam preocupações sobre sua eficácia em termos econômicos e humanos. (Pinheiro-Machado, 2018, p. 152, tradução nossa).

Ultimamente, o mundo tem sido tomado pelo fenômeno das fake news. Através das modernas mídias sociais, qualquer pessoa pode divulgar notícias falsas. Ao serem dirigidas a milhares de receptores, essas mensagens frequentemente passam a ser consideradas verdadeiras. Na política isso pode significar a difamação ou a calúnia de adversários com resultados impactantes em eleições. Atualmente, é muito difícil imaginar qualquer campanha eleitoral em que as fake news não sejam um componente importante.

Embora considerado um fenômeno moderno, as fake news já existem há muito tempo. Os Protocolos dos Sábios de Sião, uma suposta ata em que judeus e maçons conspiram a fim de alcançarem a "dominação mundial através da destruição do mundo ocidental", foram criados durante a Rússia czarista 
e traduzidos para várias línguas no começo do século passado, alcançando grande repercussão em diferentes países. Os nazistas usaram o texto como justificativa de seus ataques aos judeus. Embora denunciado como um embuste, 0 opúsculo continua em circulação até hoje, principalmente na internet. No Brasil, durante a República Velha, parte da imprensa difundiu supostas cartas do presidente Arthur Bernardes em que ele ofendia os militares. Apesar dos desmentidos, essas falsificações causaram uma tensão muito grande. Igualmente no Brasil, em 30 de setembro de 1937, o chefe do Estado-Maior do exército brasileiro anunciou no programa radiofônico A Voz do Brasil o Plano Cohen, um documento falsamente atribuído à Internacional Comunista, mas na verdade elaborado por militares com a finalidade de simular uma revolução judaico-comunista no país. Depois do anúncio, Getúlio Vargas conseguiu que o Congresso Nacional decretasse o estado de guerra. Em 10 de novembro do mesmo ano, ele implantou a ditadura do Estado Novo, que durou até 1945. Depois da guerra, foi revelado que o autor da farsa foi o capitão Olímpio Mourão Filho, membro da Ação Integralista Brasileira, que em 1964, já como general, teve um papel determinante no golpe de estado que depôs o presidente João Goulart.

A falsidade como uma práxis política é um fenômeno analisado por Nils Bubandt e Rane Willerslev nas suas leituras contemporâneas da mimesis. Eles enfatizam a ambiguidade das capacidades miméticas, afirmando que

identificações empáticas com outros não têm como objetivo a compreensão mútua, o altruísmo, a consolação, a compaixão intersubjetiva, o cuidado, ou a coesão social - objetivos convencionalmente vistos como a sine qua non da empatia. Em vez disso, a faculdade empática é usada para propósitos enganosos e ultimamente violentos. (Bubandt; Willerslev, 2015, p. 6, tradução nossa).

Eles chamam esse fenômeno de "empatia tática", um mecanismo que parece "estar subjacente a muitas das formas cotidianas de falsidade" (Bubandt; Willerslev, 2015, p. 9, tradução nossa). Do mesmo modo que um caçador pode fingir ser da mesma espécie de sua presa para enganá-la e assim conseguir abatê-la, assumir a identidade de um adversário e espalhar notícias falsas como se elas partissem dele é uma técnica de grande impacto.

As diferentes formas de imitações, simulacros e de falsificação são mecanismos que fazem parte da modernidade, mas não só. Encará-los apenas como 
mentiras não nos permite perceber aquela que talvez seja uma das mais eloquentes disposições humanas: a criatividade. A riqueza subjacente a essa problemática é inesgotável, pois as constantes mudanças em termos culturais, políticos e econômicos, reconfiguram os arranjos entre autenticidade e imitação, realidade e simulação, originalidade e falsificação. Em torno desse tema o que não são falsas, nem raras, são as controvérsias.

Este número de Horizontes Antropológicos apresenta um conjunto de textos que abordam a temática sob os mais variados aspectos, tanto do ponto de vista empírico quanto do teórico. Os objetos são variados e são múltiplas as nacionalidades dos autores e as filiações institucionais. Como é característica dos números temáticos deste periódico, não há uma busca a priori de articulação entre os diferentes artigos, de modo a retratar um suposto estado da arte ou algo equivalente. A sequência sugerida é uma possibilidade, entre outras, de encadeamento dos artigos, uma vez que eles bem podem ser aproximados ou confrontados sob outras perspectivas.

Em "Brincando de bonecos: um ensaio benjaminiano sobre mimesis", John C. Dawsey e Claudia da Silva Santana tratam do que eles chamam de "circuito mimético", dinâmica em que se entrelaçam dramas sociais e produções estéticas. Os autores consideram que a produção dos bonecos precisa ser compreendida dentro de um contexto de drama social experienciado pelos moradores locais, das margens no rio Piracicaba, interior de São Paulo. A tentativa de povoar simbolicamente o rio com bonecos e imagens de antepassados, que fizeram suas moradas às suas margens, e de índios paiaguás ou evuevi - "gente do rio" -, seria uma tentativa de fazê-los não sair de suas margens em um momento em que se veem ameaçados por um projeto da prefeitura de "reconquista da Rua do Porto", associado à restauração de um imaginário bandeirante. Num texto denso e pontuado pela experiência etnográfica, Dawsey e Santana chamam a atenção para o modo como os resíduos da cidade e da sua história ganham vida na forma dos bonecos.

Em "Mimesis, dúvida e poder: divindades hindus e espíritos de colonizadores na Guiana", Marcelo Moura Mello procura explorar, através da descrição das interações entre espíritos de colonizadores, especialistas religiosos, divindades e devotos da deusa Kali, de que forma concepções nativas sobre a presença de entes espirituais no mundo são atravessadas por dúvidas, hesitações e (re)elaborações retrospectivas de eventos passados, bem como por reflexões 
aguçadas sobre as potencialidades de seres com estatutos ontológicos distintos assumirem, incorporarem e imitarem atributos e poderes de outros seres. Os espíritos de colonizadores holandeses na Guiana seriam responsáveis por causar uma série de doenças e aflições entre membros e frequentadores dos templos de Kali. Essas entidades originaram-se, segundo uma narrativa muito difundida, após as disputas entre colonizadores holandeses e britânicos, nos primeiros anos do século XIX. Os espíritos seriam os "verdadeiros senhores da terra" e teriam uma predileção por possuir e atacar pessoas que vivem nesses locais, causando-lhes transtornos por vontade de vingança, doenças, confusões mentais, desejos desmedidos, como compulsão por bebidas alcoólicas e libido aflorada, além de precipitarem suicídios.

"O simulacro da Rainha: performance, ritual e corpo no Reisado Santa Helena", de Ribamar José de Oliveira Junior e Lore Fortes, trata da performance de Francisca da Silva, mais conhecida como Tica, brincante da tradição cultural do Reisado no figural de Rainha no grupo Santa Helena, em Juazeiro do Norte, interior do Ceará. Esse ritual é o ponto de partida para uma reflexão sobre gênero, corpo e sexualidade a partir do tema da performance mimética em seu caráter subversivo. Os autores interpretam a rainha Tica como uma entidade que manifesta a dissidência sexual e de gênero por meio do uso do corpo na repetição da performatividade feminina a partir dos eixos de precariedade e de vulnerabilidade. Nisso, se contrapõem a uma abordagem essencialista da cultura popular e propõem uma abordagem que privilegia os processos inventivos nas tradições culturais locais.

Louise Scoz Pasteur de Faria e Ruben George Oliven nos convidam a refletir sobre perfis falsos de celebridades, um tema contemporâneo que entrelaça imitação, tecnologias de mídias digitais e a experiência da alta modernidade. Para tanto, exploram etnograficamente a vida dentro e fora da internet de @hebecamargo, perfil criado pelo guru de mídias sociais Victor Calazans. O perfil adquiriu projeção nacional após ser noticiado como sendo o perfil oficial da apresentadora, no episódio de sua primeira internação hospitalar em 2010, por um grupo de mídia brasileiro. A partir de contribuições de pesquisas relacionadas a etnografias de fakes, os autores ressaltam a importância de pensar essas entidades como agentes que emergem a partir de um pano de fundo de dinâmicas latentes da modernidade tardia em relação a poder, mídia e subjetividade. A emergência de perfis falsos de celebridades em plataformas de mídias sociais 
é o ponto de partida para pensar nos modos através dos quais nos envolvemos com tecnologias digitais, na importância da imagem e na "falsidade" (fakeness) como elementos que não podem ser dissociados na cadeia produtiva contemporânea dos media.

Alice Villela, no artigo "Imagem, imitação, presentificação: ambiguidade e agência das imagens produzidas pelas tecnologias dos brancos", busca compreender o modo como imagens fotográficas e audiovisuais são capturadas e compreendidas pelos Asuriní, grupo indígena que vive no médio curso do rio Xingu. Desde o contato oficial em 1971 até os dias atuais, as imagens produzidas pelas tecnologias dos brancos são marcadas, da perspectiva asuriní, pela ambiguidade e iminência de produzir efeitos, muitas vezes nefastos. Existiria, segundo a autora, uma relação intrínseca entre a noção de imagem (ayngava) e o princípio vital (ynga). A partir dessa perspectiva, a imitação não seria uma mera reprodução do que está ausente ou representação do real, mas sim aponta para um estatuto da imagem viva em que o referente se presentifica ou é evocado, capaz de influenciar o ente humano ou não humano representado por compartilhar sua força vital. Tal concepção de imagem não cria a oposição entre verdadeiro e falso, ou verdadeiro e ilusório, mas povoa o mundo social com novas agências e novas possibilidades de ação sobre o mundo.

Gabriela Schiavoni, no artigo "Imitar y fabricar. Las naturalezaculturas de las agriculturas guaraní, colona y agroecológica", inscreve o processo mimético no contexto de práticas agriculturais das populações autóctones e imigrantes na província de Misiones, na Argentina. Schiavoni propõe a noção de naturezasculturas (nature-cultures) para descrever o modo como essas populações pensam e produzem técnicas agriculturais de modo análogo à natureza, guiadas por princípios de similitude, simbiose e contágio entre agentes humanos e não humanos. A autora argumenta que, ao contrário da tradição construtivista e materialista que toma o processo mimético como anterior à representação simbólica, a lógica mimética seria um contínuo que permite a conexão entre agentes humanos e não humanos. A materialidade não é, portanto, algo para ser "domesticado" pela ação humana, mas sim o próprio agente que molda e transforma a ação humana. Assim, a natureza é entendida como um processo no qual associações são estabelecidas por contiguidade, através de séries de identificações sucessivas nas quais plantas, animais, seres humanos e entidades suprassensíveis participam. 
Em “'Agro é tudo': simulações no aparato de legitimação do agronegócio", Caio Pompeia investiga as operações narrativas relacionadas à proposição "agro é tudo", entendida como parte de tecnologias políticas operadas para superestimar a representatividade efetiva desses agentes e ampliar a eficácia de seus pleitos. A relação entre agentes do agronegócio, Estado e opinião pública seria marcada por uma estratégia de "sinédoque política", dinâmica global que tem contribuído significativamente para justificar agendas políticas em situações de controvérsias públicas. Nesse contexto, grupos de interesse buscam simular uma representatividade ampliada aos olhos da opinião pública e do Estado. As simulações, que se iniciam com o agenciamento da sinédoque, completam-se com o simulacro - ideia de núcleos do agronegócio com super-representação que resulta em uma construção hiper-real que se projeta sobre a efetiva abrangência política dos agentes do agronegócio. Essa é uma tática contemporânea de mobilização que tenta fixar um imaginário ampliado atrelado a pautas políticas de grupos de interesse com o objetivo de justificar a ação de seus agentes e o endosso do Estado e da opinião pública.

Em "Fronteras y contrabando: etnografía del comercio de mercancías-imitaciones en la Espacialidad Fronteriza de Atacama-Lípez (EFAL) (Chile y Bolivia)", José Miguel Muñoz Valenzuela trata do contexto contemporâneo da circulação de produtos-imitação provenientes do leste da Ásia nos circuitos comerciais e de contrabando na fronteira entre o Chile e a Bolívia. Muñoz Valenzuela reflete sobre práticas de imitação e falsificação a partir das dinâmicas político-econômicas mais recentes de "border work", conceito cunhado por Madeleine Reeves (2014), que se refere aos modos como a ideia de territorialidade estatal estão moldando e acirrando conflitos e negociações globais sobre fronteiras internacionais. Nesse contexto, a demarcação de fronteiras nacionais, o policiamento das fronteiras, a história e a trajetória local, assim como os conflitos da passagem, são elementos que marcam a experiência subjetiva dos sujeitos entre fronteiras, chamando a atenção para a necessidade de repensar o contrabando à luz dessa política econômica emergente.

Luiz Henrique de Toledo, em "Antijogo: considerações em torno de uma categoria da diferença", problematiza a categoria nativa de antijogo, circunscrita em princípio aos domínios esportivos e extensiva ao cotidiano a partir de metáforas que facilmente escapam da seara originária. Antijogo, como má conduta, comumente tipificada como uma ação individual correlacionada às práticas 
esportivas, também remete à sociabilidade em contextos nos quais significa burla e contrafação. Neste artigo o autor não apenas revê criticamente a noção de antijogo como suposta antítese daquilo que ao longo do tempo se estabeleceu como substrato dos esportes, isto é, os jogos e passatempos desdobrados no interior dos Estados nacionais, tomando o futebol como exemplo, mas também enfrenta uma questão metodológica que assume o regime da diferença e não necessariamente o da identidade como fundamento das conceitualizações repostas em noções correntes que amparam algumas definições de jogo e, por simples inércia antagônica, as de antijogo.

Por fim, a seção Espaço Aberto apresenta uma entrevista com Philippe Descola, concedida a Mariana Bombo Perozzi Gameiro, David Dupuis e Carla Forte Maiolino Molento. Nela, o titular da cátedra de Antropologia do Collège de France analisa a condição animal sob o prisma da virada ontológica.

A capa deste número de Horizontes Antropológicos é o óleo Autorretrato com máscaras do pintor belga James Ensor (1860-1949), considerado o fundador e líder do grupo avant-garde Les XX (Os 20), cujo objetivo era promover novos desenvolvimentos artísticos na Europa e que teve uma importante influência no expressionismo e no surrealismo.

\section{Referências}

ANDRADE, O. de. Manifesto antropófago. In: ANDRADE, O. de. Do pau-brasil à antropofagia e às utopias. Rio de Janeiro: Civilização Brasileira, 1978. p. 11-19.

BENJAMIN, W. A obra de arte na época de sua reprodutibilidade técnica. In: LIMA, L. C. (org.). Teoria da cultura de massa. Rio de Janeiro: Saga, 1969. p. 203-238.

BHABHA, H. The location of culture. New York: Routledge, 1994.

BUBANDT, N.; WILLERSLEV, R. The dark side of empathy: mimesis, deception, and the magic alterity. Comparative Studies in Society and History, v. 57, n. 1, p. 5-34, 2015.

BURKE, P. Inevitáveis empréstimos culturais. Folha de S. Paulo, São Paulo, 27 jun. 1997. Caderno 5, p. 3.

COLTON, C. C. Lacon, or, many things in a few words: addressed to those who think. New York: S. Marks, 1824.

DORSON, R. M. Fakelore. Zeitschrift für Volkskunde, n. 65, p. 56-64, 1969. 
DUNDES, A. Nationalistic inferiority complexes and the fabrication of fakelore: a reconsideration of Ossian, the Kinder- und Hausmärchen, the Kalevala, and Paul Bunyan. Journal of Folklore Research, v. 22, n. 1, p. 5-18, 1985.

FERGUSON, J. G. Of mimicry and membership: Africans and the "New World Society". Cultural Anthropology, v. 17, n. 4, p. 551-569, 2002.

HART, K. The memory bank: money in an unequal world. London: Profile, 2000.

HOBSBAWM, E.; RANGER, T. A invenção das tradições. Rio de Janeiro: Paz e Terra, 1984.

LINTON, R. O homem: uma introdução à antropologia. São Paulo: Livraria Martins Editora, 1962.

MAUSS, M. As técnicas corporais. In: MAUSS, M. Sociologia e antropologia. São Paulo: Cosac \& Naify, 2003. p. 401-422.

MAYET-GIAUME, J.; ROUCH, J.; VOS, G. de. La polémique autour des “Maîtres fous". CinemAction, n. 81, p. 81-88, 1996.

MORAES, E. J. de. A brasilidade modernista: sua dimensão filosófica. Rio de Janeiro: Graal, 1978.

OLIVEN, R. G. As metamorfoses da cultura brasileira. In: OLIVEN, R. G. Violência e cultura no Brasil. Petrópolis: Vozes, 1989. p. 61-73.

OLIVEN, R. G. Um antropólogo brasileiro numa universidade norte-americana. Horizontes Antropológicos, Porto Alegre, ano 3, n. 5, p. 225-244, 1997.

PINHEIRO-MACHADO, R. Counterfeit itineraries in the Global South: the human consequences of piracy in China and Brazil. London: Routledge, 2018.

PRICE, S. Arte primitiva em centros civilizados. Rio de Janeiro: Editora da UFRJ, 2010.

REEVES, M. Border work: spatial lives of the state in rural Central Asia. Ithaca: Cornell University Press, 2014.

RIBEIRO, G. L. O que há em uma cópia?. In: RIBEIRO, G. L. Outras globalizações: cosmopolíticas pós-imperialistas. Rio de Janeiro: Editora da UERJ, 2014. p. 249-267.

SCHWARZ, R. Ao vencedor as batatas. São Paulo: Duas Cidades, 1977.

TAUSSIG, M. Mimesis and alterity: a particular history of the senses. New York: Routledge, 1993. 